\title{
Cultural Literacy: A Critical Reflection for Climate Change Mitigation
}

\author{
Christiana Uzoaru Okorie \\ Lecturer, Department of Adult and Non-Formal Education, University of Port Harcourt
}

\begin{abstract}
This paper discussed the importance of cultural practices toward climate change. In Nigeria, many communities engage in different cultural practices which have over the years protected the ecosystem. The environment and its associated resources both living and non-living things are culturally accorded values, guide the usability of such environmental resources and protect the ecosystem. But toady these cultural practices have been lately replaced with modern ways of life with its associated science and technology and climate change. to mitigate or reduce the impact of climate change need a turn around to some traditional ways of utilizing the ecosystem which the culture of tree planting is one them. The culture of tree planting skill is a necessity for the safety of our environment from climate change impact because one tree planted can purify polluted air due to climate change, absorbs tons of carbon and creates several kilogrammes of oxygen.
\end{abstract}

Keywords: Culture, Cultural Practices, Cultural Literacy, Climate Change, Climate Change Mitigation

DOI: $10.7176 / \mathrm{JEP} / 12-36-07$

Publication date: December $31^{\text {st }} 2021$

\section{Introduction}

Culture and environment are inseparable, every society has its own culture related patterns which represent their traditional ways of sustaining the environment. In most Africa society, culture of reference to different environmental resources, mostly plant and animal is part of our traditional ways of sustaining the ecosystem. Many African traditional cultures stressed strong relationship with the environment through their culturally acceptable environmental management processes such as strictures and taboos on different environmental components. For example, in some places in Nigeria, some rivers, streams, ponds are reverence as scared and people are not allowed to swim, bath of fetch the water. In such water bodies, people are permitted to fish or catch any aquatic organism living found in it due to ancestral belief attach to these water bodies. In some other places certain forested area are called sacred forest where people are not permitted to enter or cut down trees in the area, all organisms found in these forests are also regarded as sacred and not to be consumed by human been because are food for gods of the land. Also, some animals are not consumed by different cultures due to their ancestral belief system which categorized these animals as ancestors.

Sibanda (1997) pointed out that African spiritualism (the belief in the supernatural) creates respect for animals, reverence for forests, rocks, mountains, and rivers, this gives an explanation as to why certain places are revered and certain activities tabooed. She further explained that natural phenomena have spirits that define the relationship between humans and nature that is inter-linked and interdependent. In same vein, Gumo, Gisege, Raballah \& Ouma (2012), asserted that humanity is part of the universe which is full of animals, plants and inanimate objects, that all these components are related to each other in various ways and the relationship between humanity and the surroundings are in different categories, depending on the use to which humankind puts them, and on the beliefs which developed in the creation of myths. All these traditional practices are practical indigenous ways of conserving the environment and environmental resources. Human and their practice of respect for nature is a typical African culture rooted in African mythology. Myth is the historical explanation of origin of indigenous customs and belief system that are basically practiced by all African communities.

In Nigeria society, most communities' environmental conservation is borne out of their mythological practices and this created the awareness of environmental value among the community members. This is in line with Sibanda (1997) observation that conservation values have grown out of the awareness that natural resources are part of that which ordinary humans do not control, invent or create, consequently, Africans do not tamper with what they do not understand or control rather they relate all this to a Superhuman Being, and an Omnipresent God who controls its processes and the preceding leads to respect for natural environmental resources.

Nigeria agrarian communities' practice traditional shifting cultivation, due to the communal land ownership inherent in some communities, farmlands are not individually owned, most farmland are usually designated place a little far away from where people build houses.

Communities that their terrain is prone to yearly flooding, have their different traditional early warning signs of flooding, traditional ways of mitigating and adapting to flood. Many animals, other forest resources (trees), ponds, rivers and some aquatic lives are branded sacred and worshiped gods of the land. All these practices are inherent in culture of the community members and are traditional environmental conservation practices which were helping to sustain the environment. These cultural practices require a critical reflection on for mitigating 
anthropogenic climate change impact and promoting environmental sustainability. People ways of life, which is their culture influences environmental sustainability due the intrinsic links between cultural diversity and biodiversity and this call for understanding of people culture through cultural literacy development.

\section{Concept of Culture}

Culture is defined by different authors from either sociological, anthropological or historical perspectives. Either of the perspective culture is defined, translate to people and their specific societal ways of living and interactions. Culture can be pragmatically defined by the contents and boundaries of the interests of the scholars who study it. Jahoda (2012) argued that "the concept of "culture' is probably indispensable," yet it cannot be defined definitively. Johoda (2012) further asserted that the concept of culture is much of the time quite practicable and defensible and defensible simply to use the term without seeking to define it. That if either for a theoretical or empirical reason clarification is essential, then the author should explain the specific manner in which she employs the term culture in that particular context. Hofstede in UKEssays (2018) viewed culture as a system of collectively held values and based on this view, culture was defined by defined Hofstede in UKEssays (2018) as the collective programming of the human mind that distinguishes the members of one human group from those of another.

Culture can also be defined as people's social heritage which include the sum total of their historical achievements or product of their social life which is been transmitted from one generation to the other in form of tradition. Culture is a key concept to the sociological perspective, sociology understands culture as the languages, customs, beliefs, rules, arts, knowledge, and collective identities and memories developed by members of all social groups that make their social environments meaningful. Sociologist belief that culture influences not only language but the gestures we use when we interact, how far apart we stand from each other when we talk, and the values we consider most important to pass on to our generation, thus culture from sociological point of view influences people's beliefs and behaviors and without culture, we could not have a society.

Anthropology takes quite a different approach to culture. Most anthropologists would define culture as the shared set of (implicit and explicit) values, ideas, concepts, and rules of behaviour that allow a social group to function and perpetuate itself. According to Kropp in Hudelson (2004) culture is understood as the dynamic and evolving socially constructed reality that exists in the minds of social group members. Kropp in Hudelson (2004) asserted that culture is the "normative that allows group members to communicate and work effectively together. It is an empirical question as to whether members of an organization have a shared culture.

Culture from historical point of view applies to materials, practices, representations, thoughts, and feelings, it is a set of beliefs, practices, and symbols that are learned and shared, together, they form an all-encompassing, integrated whole that binds people together and shapes their worldview and lifeways. Historically, the meanings of culture not only vary from one group to another, but that all human societies define themselves through culture. In view of this, Giddens (2005) pointed out that culture is the ways of life of the members of society, or of groups within a society which includes how they dress, their marriage customs, language and family life, their patterns of work, religious ceremonies and leisure pursuits.

The concept of culture form either sociological, anthropological or historical point of view bring into mind some attributes which that are important to human, these attributes are:

1. Culture is manmade: it is created by man and is passed from to generation to generation

2. Culture influences human behaviour and interactions in the society they find themselves

3. Culture can be influence, changed or dominated by evolution of time. Some culture over time can be described as obsolete and are either discarded, terminated or modernized (for instance female genital mutilation, killing of twins, burial rites in some regions in Nigeria, clothing styles in Africa, and so on.

Culture is a very important aspect of human life that conditions human perception of the world, influences what human considers as important, and also specify appropriate and inappropriate course of human action within the society in which they find themselves. Culture and society are inseparable because culture cannot exist without society and society cannot exist without culture. For society, to continue to exist there is need to preserve the society cultural heritage through collective consciousness. Itulua-Abumere (2013) asserted that without culture, we would not be 'human' at all; we would have no language in which to express ourselves; no sense of selfconsciousness; and our ability to think or reason would be severely limited.

Culture is made of two components which are material culture and nonmaterial culture Material components of culture include those physical objects that people create and use, or objects that to a group of people. For example, food clothing, tools, cooking utensils, hairstyle, jewelry, architecture (building), and so on. While nonmaterial culture is the abstract (intangible) human creations which include beliefs, ideas, family pattern, language, political and economic system, skills, arts, ethics, rules, social roles, work pattern, and so on. Both material (tangible) and nonmaterial (intangible) components of culture are crucial in guiding the behaviour of all members of any society and heir interaction within and outside their society. material and nonmaterial culture make up the elements of culture in which we study today. In same vein, ogundele (2000) asserted that cultural heritages are categorised into material/tangible and non-material/intangible cultural heritages, because culture in 
itself is "both physical and non-physical in character".

\subsection{Cultural Practices and Environment \\ 2.1.1. Norms and the Environment}

Norms refer to conditions for social relations between groups and individuals, for the structure of society and the difference between societies, and for human behavior in general. Norms are shared rules, customs, and guidelines that govern society and define how people should behave in the company of others. Norms may be applicable to all members of society or only to certain subsets of the population. Norms guide smooth and peaceful interactions by prescribing predictable behavior in different situations. Norms are guidelines and rules of behaviour expected from the individual in specific situation,

Norms tend to be institutionalized and internalized. Most social control of individuals through norms is internal and guided by the pressures and restraints of cultural indoctrination. Individual cultures sanction their norms. Sanctions may be rewards for conformity to norms or punishment for nonconformity. Positive sanctions include rewards, praise. Negative sanctions include the infliction of guilt, condemnation, citations, fines, and imprisonment (Opp, 1979). Norms are different from values, values are individual or, in some instances, commonly shared conceptions of desirable states of being. In contrast, norms are generally accepted prescriptions for or prohibitions against behavior, belief, or feeling. While values can be held by an individual, norms cannot and must be upheld by a group. Norms always include sanctions but values never do.

\subsubsection{Values and the Environment}

In all human society, values are fundamental and this dictates the direction of human actions and activities within and outside their society. Dania and Igbanibo (2016) observed that values are derived from cultural system and that they are the broad preference pertaining appropriate courses of actions or outcomes which reflect a person's perception or view of right or wrong and tend to influence attitudes and behaviour. Values are intangible qualities or beliefs accepted and endorsed by a given society which are distinct from attitudes, traits, norms, and needs.

Kaur and Kaur (2016: 224) define values as intangible (nonmaterial culture) qualities or beliefs accepted and endorsed by a given society which is distinct from attitudes, traits, norms, and needs. They further explained that values:

1. tend to be unobservable;

2. tend to be conflated with other social and psychological phenomena;

3. tend to have historical and cultural variability; and

4. express an idealized state of being.

In traditional Nigeria cultural system, the environment and its associated resources both living and non-living things are accorded values and this guide the usability of such environmental resources. Values influence individual and group action. Values influence attention, perception, and interpretation within situations and ultimately influence the planning of individual and group action. According to Bewaji (2012:3):

there are clear values relating to nature, all aspects of nature, that

in many communities, trees, rivers, caves, and other natural resources have assisted the communities to survive in the past. Some of these natural resources have provided special nourishment in times of need, some have been places of shelter during wars or natural disaster, and some have been the fall back resources when all else seemed lost. For this reason, all things in nature deserves respect, recognition, and attention, so that they can continue to be useful and sources of sustenance to future generations.

In some Igbo culture, land, trees, rivers, animals, birds, and so on are valuable asset which are valued as much as human beings are valued. The values accorded to these environmental resources contributed to their sustainability. For example, the culture of evil or sacred forest inherent in some igbo culture contributed to sustenance of forest in Igboland. Value were accorded to these forest as ancestral home and home for the spirit. Okorie and Mbalisi (2019) observed that in most rural communities in Eastern part of Nigeria, trees were formally planted around the home for the purpose of establishing boundaries between households. Others are planted at the center of the compound to indicate the presence of a deity, which protects the household. Some are planted at the village or market square for some significant religious beliefs attached to the trees. The traditional value attached to tree planting around the home is not only the significance importance of trees but to the traditionalist, their anthropocentric view of tree is the reason. Trees according to Okorie and Mbalisi (2019) are essential to wellbeing of man on earth because they are primary sources of oxygen and carbon dioxide, they absorb and cleanse environmental contaminants from the air, moderate the climate, conserve water and soil for sustenance of life on earth. 


\subsubsection{Taboos and the environment}

Taboos relate to traditional worldviews in biodiversity and ways of life in which humans lived close to nature and recognized the connectivity and interdependence of all living things, human, plants and animals. Ossei (nd) pointed out that taboo is any sort of social prohibition imposed by the leadership of a community regarding certain times, places, actions, events, and people etc. especially, but not exclusively, for religious reasons for the well-being of the society., which are used in narrower sense to represents the cultic or purely usage, or to represent the broader sense in socio-economic and political contexts. Taboos represent the main source of guiding principles regulating and directing the behavior of individuals and the community towards the Supreme Being and especially the gods and the ancestors in African traditional societies.

The taboo system was the main source of bonding in all human relations and transactions in traditional societies mostly environmental taboos. Environmental taboos are those taboos that the traditional authorities put in place to regulate the ethical use of the environment and its resources for the ecology and sustainable development. Example of environmental taboos are not clearing of sacred forest, not felling of forbidden trees, not hunting of some forbidden animals, not fishing in forbidden ponds and rivers, lakes, not eating of forbidden animals, and so on. Taboos are traditional ways of maintaining biodiversity because many specific-species that are threatened are protected by taboos. But today, many of these species have gone into extinction because their natural habitats have been displaced due to anthropogenic factors.

\subsubsection{Morality and Environment}

Morality is one of the guiding principles of any traditional society, Ogugua and Jude (nd) observed that what constitutes moral code of any particular Nigerian society. the laws, taboos, customs and set forms of behavior-all derive their compelling power from religion. Thus, morality flows out of religion, and through this the conduct of individuals are regulated; and any break of the moral code is regarded as evil and punishable.

\subsection{Concept of Cultural Literacy}

Cultural literacy denotes literacy component of people culture, ability to read and write and understand other people's culture. Hirsh (1987) popularized the concept of cultural literacy when he argued that to participate fully in society, a person needs more than basic literacy, that early education should focus on content and that all students could achieve cultural literacy. In support of this, Shamshayooadeh (2011) stressed that cultural literacy is an indispensable pedagogical tool we need to internalize the basic, factual and cultural information, which in turn will enable us to analytically critique and analyze various cultural, historical, and political phenomena by looking at them in a more critical light. Polistina (2007) explained that cultural literacy includes cultural competence but adds to it the ability to critically reflect on, and if necessary, bring about change in, one's own culture, which also includes the ability to analyse the behaviours of dominant cultures in relation to other cultures. The author further emphasized that cultural literacy entails four skills which are cross-cultural awareness, local cultural awareness, critical reflection and thinking, and personal skills for coping with being change agent which learners need.

Cross-Cultural Awareness Skills: This includes the ability to examine other cultures critically and gain ideas about sustainability from them.

Local cultural awareness: This is the ability to accept and respect knowledge within local cultures and communities. Polistina (2001) pointed out that there may be knowledge and skills for living sustainably that are already embedded in the traditions of local cultures and passed on intergenerationally through nonformal education. Critical Reflection and Thinking: This is a dialogue-based way of understanding people's culture. Ghaye and Ghaye (2001) was of the view that critical reflective thinking is a dialogue between learners and educators on aspects of cultural or social discourse; it considers the experiences of the group as a whole and provides a way of accounting for ourselves.

Personal skills for coping with being a change agent: Learners need to 'survive' being change agents for this cultural shift as they will encounter a variety of mental, physical, psychological and emotional battles with those seeking to sustain the status quo. Learners and educators need to be empowered to cope with cultural and social power-brokers unreceptive behaviours. Learners will need skills in seeking out reliable, upto-date and accessible information on climate change.

\subsection{Concept of Climate Change}

Climate change is a global problem that is affecting all countries in the world, it is a long-term shift in average weather conditions such as temperature, rainfall, and son on in different world regions. Climate change was originally conceived by scientist a natural process due to possible changes in earth's orbit, energy output of sun, geographic distribution of earth's land masses and other nature-related activities. But today the variability in average weather conditions of earth continued to vary due to different anthropogenic (man-made) factors. The concept of climate change has been reestablished to have gone beyond nature related activities to man-related activities. Human in their cause of carrying out their developmental activities, carry out different actions that in one way or the other led to climate change we experience today. Some of such anthropogenic activities include 
burning of fossil fuels (oil, coal and natural gas), clearing of forest for farming, construction, ranching. These activities release greenhouse gases (carbon dioxide, methane, halocarbons, and nitrous oxide) into atmosphere Also some of our everyday social lie such as eating, working, moving about, and heating and cooling our homes result in emissions of greenhouse gases that contribute to climate change.

Shove, Pantzar \& Watson (2012) asserted that climate change is embedded in everyday practices such as the way we light, heat and cool our homes, move about and eat. All these activities in one way or the other, releases greenhouse gasses which accumulate in the atmosphere and allow radiation from the sun to pass through, but it also traps some of the heat radiating back from the Earth (greenhouse effect). It is the continuous greenhouse effect over a long period of time that increases the earth's average temperature (global warming) and other changes in climate. Thus, global warming with associated changes in climate such as rainfall patterns and the frequency and distribution of weather events such as droughts, storms, floods and heat waves are collectively referred to as climate change. Thus, Climate change is a change in either the average climate or climate variability that persists over an extended period. UNFCCC (1994) cited in Rahman (2013) defined climate change as "a change of climate which is attributed directly or indirectly to human activity that alters the composition of the global atmosphere and which is in addition to natural climate variability observed over comparable time periods".

\subsection{Culture and Ecosystem}

Culture of people has direct impact on their usability of ecosystem, through culture, ecosystem is modified to fit into the cultural practices, values, and visions of a given society. Riedy (nd) pointed out that human culture is strongly influenced by ecosystems, and ecosystem change can have a significant impact on cultural identity and social stability. The connection between cultural literacy and climate change in this paper is rooted from the functionalist view of society. Functionalist emphasize that society consist of inter related parts which work for the integration and stability of the whole system. The integrated parts as conceptualized in this paper is the cultural traits that are useful parts of the society which include cultural values, norms, beliefs, attitude, which come together to perform function within the society. In some traditional Nigeria society, culture shape the way in which community members carry out their socio-economic/developmental activities, it is through culture that most of the activities that contribute to climate change today are termed due the values and spiritual attachment to these environmental resources. For instance, trees planting was traditionally embedded in most culture in Nigeria, In the Eastern part of Nigeria, trees are planted for boundary purpose, medicinal purpose, protection, purpose, economic and spiritual attachment.

Trees are essential to well-being of man on earth because they are primary sources of oxygen and carbon dioxide, they absorb and cleanse environmental contaminants from the air, moderate the climate, conserve water and soil for sustenance of life on earth and above all prevent climate change. Traditional culture place some trees as sacred species that are not to be cut down, for example the iroko tree. Iroko trees are regarded as Oke Osisii in igbo land, they are accorded respect in anywhere they are found in the farm, home or community square. This cultural value contributed to the growth of giant iroko trees which serve as ancestral places. Also, economic trees such as palm tree are not cut down for palm wine tapping, rather when you tap the palm tree for wine, you do it respectfully without cutting the shoot. Bewaji (2012) explained that even though cutting down the palm tree will give you more juice, it is abomination to cut it down, it is the height of abomination to uproot the palm tree, set fire to it at the bottom, to drain the juice from the top, even though what you get will be instantly more potent. Another significant importance of trees in Igbo culture, is when a girl is given out for marriage, her parent in their first visit will $g$ with economic trees young plant to plant in her husband place as a sign of fruitfulness and economic empowerment. This culture produced abundant tree planting across the Igbo socio-cultural society. Our traditional socio-cultural practices recognized the importance of tree, despite the fact they are ignorant of its ecosystem carbon sink importance.

Today modernization have eluded the culture of traditional tree planting and the environment in which these trees protect are left bare due to absence of trees and the effect is climate change. Onuma, Raballah, Gisege \& Gumo (2101) asserted that African communities accept the interdependence between nature and humans. They comprehend that life is only possible if natural environmental resources continue to be available for human use. To them, conservation values and practices do not come from law enforcement but from both spiritual and social responsibility that has grown from the desire to survive in an attempt to evade punishment from the spiritual world. This is in support of Omare (2006) observation that various African worldviews of soil fertility and rain frequencies are contingent upon the vitality of certain wildlife populations, that the killing of sacred animals, felling of sacred trees and destruction of sacred spaces in the forest only meets with spiritual disapproval, which manifests itself in the form of great droughts or disease outbreaks. Also, degradation of natural resources used for spirituality, such deforestation and unexpected fire breakage, would naturally destroy traditional shrines and spell out doom for the community members. However, to avoid the unforeseen doom, the environmental resources are rationally used in such a way that promote environmental sustainability, exploitation of natural resources was checkmate through cultural norms. The rationality attached to usage of resources due to cultural values and norms are essential 
component of African traditional culture that can be tapped for climate mitigation.

\subsection{Modernization, Culture and Climate Change Impact}

In Nigeria society today, modernization have swallowed up our different cultural practices, many communities are no longer practicing their traditional cultural ways of environmental sustainability due to population increase and influx of alien cultures due to modernisation. Modernisation remolded African traditional cultures into a new mode, most of the traditional practices that were embedded in African traditional society that in one way or the other contributed to environmental sustainability and climate change mitigation have disappeared. Modernisation broaden and transform people's way of thinking, pattern of behaviour and worldview, it has remolded African cultural system to a new form (modern world view). This modern world view has in turn change the perception of local communities in Nigeria concerning:

1. their relationship with the ecosystem;

2. environmental resource usability; and

3. consumption pattern

Many activities practiced before the advent of modernsation, are regarded as archaic and are replaced with ideology. Cultural values and norms are regarded as barbaric. This modern world view is associated with modern ways of carrying out human developmental tasks accompanied with science and technology. Traditional cultural practices that has in one way or the other contributed to activities which protect the environmental resources, checkmate consumption pattern and promoted rational usage of environmental resources have been replaced with modern ways that have expose the ecosystem to different greenhouse gas emission resulting to climate change.

\subsection{Need for Cultural Tree Literacy Planting}

One of the foremost traditional worldviews of environmental sustainability is embedded in their culture of tree planting. Traditionally in some Igbo culture, it is believed that trees signify life. For example, the people of OnichaIgboeze previously plant a particular tree called $O g b u$ at the center of every household, this tree stand as right to any piece of land it is planted on an also symbol of longevity. It is traditionally believed that $O g b u$ trees does not die easily, that even if it branches are shredded, the tree will survive and continue to bring forth flower. The implication of this belief to community members is that any soul that inhabit the compound where the ogbu tree is planted will experience longevity, that is case of adversity, the occupants will triumph. This tree is found all compound and they grew big and form shade where compound people sit to discuss. Other trees such as iroko, placid, oil beam tree, and so on were also planted by community members for one traditional value or the other.

The act of tree planting the community members helping keeping their environment free from climate change. Trees around the homes provided fruits, shelter, provides medicine for community members, improve the quality of air living organism breathe in (oxygen), removes carbon-dioxide from the atmosphere, reduce erosion, prevent flooding, fight excessive wind and so on. The tree planting traditional culture have been negatively impacted by modernization, mostly due to increase in population growth and quest for food, housing, construction, farming, technology, and so on, leading to exposure of the atmosphere to greenhouse gasses that were supposed to be purify by the presence of trees because trees serve as carbon sink. Our climate condition is seriously experiencing different climatic change impact such as poor air quality, rise in sea level, excessive heat, biodiversity loss, loss of habitat due to disappearance of forest, and so on. The continual ignorant of significant of tree planting cultural value to the environment, may led to more severe climatic change impact and threat to biodiversity and thus call for humanity to shift from modernity to traditional cultural values of tree planting by learning the tree planting literacy skills across different cultures.

\section{Conclusion}

In our traditional society, community members engage in different cultural practices which in one way or the other mitigate climate change, these traditional practices have been replaced by science and technology with its associated climate change. Climate change is today a global problem and need urgent solutions if we must save the ecosystem and biodiversity. However, we need to look back to some cultural practices that were traditionally practiced by indigenous people that were significant in protecting the environment, one of such is the culture of tree planting. Trees are essential component of the environment that not only provide food, shade, shelter and act as economic source to community members but perform the function of purifying air, remove carbon dioxide, reduce erosion, and above all reduce the impact of greenhouse gasses. Learning the cultural literacy skills of tree planting embedded in different traditional culture will help a long way to mitigate the impact of climate change.

\section{References}

Bewaji, J.A.I. (2012). Yorùbá values and the environment. College of Liberal Arts and Science. Forida University

Bewaji, J.A.I. (2016). Heritage, cultural preservation and management" in T. Falola \& A. Akintunde 
(eds.). Encyclopedia of the Yoruba, 148-149.

Dania, P. O. and Igbanibo, A. S. (2016). Culture and moral values and sustainable development in Bayelsa State: The role of social studies education. Research on Humanities and Social, 6(14), 15-19.

Giddens, A. (2005): Sociology, (4th edition), Cambridge: Polity Press

Gumo, S Gisege, S.O., Raballah, E. \& Ouma, C. (2012). Communicating African spirituality through ecology: Challenges and prospects for the 21st century. Religions, 3, 523-543.

Hudelson, P.M. (2004). Culture and quality: an anthropological perspective. International Journal for Quality in Health Care 16(5). 345-346

Itulua-Abumere, F. (2013). Sociological concepts of culture and identity. Assessed online from http://www.upublish.info/Article/The-Christian-and-Culture/816674.

Jahoda, G. (2012). Critical reflections on some recent definitions of "culture." Culture and Psychology, 18, 289303.

Kaur, A. and Kaur, M. (2016). The study of components of culture: values, norms, material objects, language and culture change. A paper presented at $6^{\text {th }}$ International Conference on Science, Technology and Management at India International Centre, New Delhi on $4^{\text {th }}$ December 2016.

Ogundele, S. O (2000). Fundamentals of archaeology: An introduction. Ibadan, Ejimasons Nigeria Enterprises.

Okorie and Mbalisi. (2019). Intergenerational Learning: Eco-Literacy Approach for Preserving Endangered Trees in Onicha Igboeze, Ebonyi State. Global Journal of Human Social Sciences: Sociology and Culture, 19(6). 41-52.

Omare, G. (2006). Role of Isukha Religious Beliefs and Practices in the Conservation of Kakamega Forest. In Religious Studies. Maseno: Maseno University

Shove, E. (2010). Social Theory and climate change: questions often, sometimes and not yet asked. Theory, Culture \& Society. SAGE Publications, 27(2-3), 277-288.

Shove, E., Pantzar, M. and Watson, M. (2012) The Dynamics of Social Practice. London: SAGE.

Sibanda. B. (1997). Environmental policy. governance, religious traditional practices and natural resource management in Zimbabwe. Zimbabwe: S.A.P.E.S.

UKEssays. (2018). Definition of culture by Hofstede Cultural Studies Essay. Retrieved from https://www.ukessays.com/essays/cultural-studies/definition-of-culture-by-hofstede-cultural-studiesessay.php?vref=1. 